\title{
El personalismo de Emmanuel Mounier y su relación con la Constitución Política de Colombia*
}

\author{
Francisco Javier Valderrama Bedoya* \\ Recibido: diciembre de 2016 \\ Aprobado: diciembre de 2016 \\ DOI: 10.22395/ojum.v15n30a12
}

\section{RESUMEN}

El presente texto se propone constatar la influencia del pensamiento de Emmanuel Mounier en la Constitución colombiana de 1991 y en el contexto que propició esa reforma constitucional. La metodología consistió en utilizar textos del autor y textos históricos que referencian el contexto vivido, en su momento, por Mounier y por Colombia en la última década antes de la Constitución de 1991. Se logró establecer que había puntos en común entre el período de 1932 a 1945 vivido por el filósofo francés y el período 1983 a 1991 vivido en Colombia. El pensamiento realista de Mounier, enfocado en la acción de la persona humana libre de cualquier idealismo o nihilismo, coincide con acciones reales de la población colombiana que hicieron cambiar los formalismos jurídicos para que se construyera un nuevo orden que, precisamente, acabara con los idealismos y nihilismos políticos y sociales del momento. Para el pensador francés, y ello se constata en la Constitución colombiana de 1991, era necesario restablecer la jerarquía moral de las necesidades de los Estados para lo cual se debían reformar las estructuras existentes, y para ello proponían una comunidad fundada en el respeto a la dignidad humana.

Palabras clave: filosofía, personalismo, Constitución, preámbulo, Estado social de derecho, fascismo, nazismo.

\footnotetext{
Este artículo se realizó como requisito de grado para optar al título de Magíster en Filosofía de la Universidad Pontificia Bolivariana -sede Medellín-Colombia.

** Licenciado en Filosofía de la Universidad Pontificia Bolivariana, abogado de la Universidad de Medellín, Magíster en Derecho de la Universidad de Medellín, doctorando en Derecho de la Universidad de Medellín profesor de tiempo completo en las áreas de humanidades y Derecho Privado del programa de Derecho de la Universidad de Medellín, correo electrónico de contacto: fjvalderrama@udem.edu.co
} 


\section{Emmanuel Mounier 's Personalism and His Relation with Colombian Political Constitution}

\section{ABSTRACT}

The present text intends to verify the influence of the thought of Emmanuel Mounier in the Colombian Constitution of 1991 and in the context that propitiated this constitutional reform. The methodology consisted in using texts of the author and historical texts that refer to the context lived in the time by Mounier and the country of Colombia in the last decade before the Constitution of 1991. It was established that there were points in common between the periods of 1932 To 1945 lived by the French philosopher, and the one from 1983 to 1991 lived in Colombia. The Realism thought of Mounier, focused on the action of the human person that is free from any Idealism or Nihilism, coincides with the real actions of the Colombian population that change the Legal Formalisms, to build a new order that would end with the Idealism and Nihilism proper of that moment. For the French thinker, and this can be seen in the 1991 Colombian Constitution, it was necessary to re-establish the moral hierarchy of the needs of States, for which the existing structures had to be reformed, and, for this purpose, he proposed a community based on respect for Human dignity.

Key words: Philosophy, Personalism, Constitution, Realism, Social State of law, Fascism, Nazism. 


\section{INTRODUCCIÓN}

A partir de 1945 el mundo posmoderno comenzó a reflexionar sobre el valor de la dignidad de la persona humana en los textos constitucionales de los Estados occidentales y es allí donde uno de los filósofos del momento se hace más visible para el pensamiento constitucional de la época como lo fue el francés Emmanuel Mounier (1905-1950). Para el pensador francés, desde el punto de vista político, era necesario restablecer la jerarquía moral de las necesidades de los Estados, para lo cual se debían reformar las estructuras estatales existentes, y para ello proponía una comunidad fundada en el respeto a la persona.

En relación con lo anterior, el 4 de julio de 1991 empezó la vigencia de la Constitución Política de Colombia, la cual, en su preámbulo y en el artículo primero, estableció como centro de su reflexión a la persona humana'. Es por ello que se plantea el problema a investigar si el personalismo de Emmanuel Mounier influyó en la actual Constitución colombiana.

\footnotetext{
PREÁMBULO: El Pueblo de Colombia, en ejercicio de su poder soberano, representado por sus delegatarios a la Asamblea Nacional Constituyente, invocando la protección de Dios, y con el fin de fortalecer la unidad de la nación y asegurar a sus integrantes la vida, la convivencia, el trabajo, la justicia, la igualdad, el conocimiento, la libertad y la paz, dentro de un marco jurídico, democrático y participativo que garantice un orden político, económico y social justo, y comprometido a impulsar la integración de la comunidad latinoamericana, decreta, sanciona y promulga la siguiente: Constitución Política de Colombia.
}

Artículo 1. Colombia es un Estado social de derecho, organizado en forma de República unitaria, descentralizada, con autonomía de sus entidades
Para lograr este propósito se relacionará el pensamiento social reivindicador de la persona humana entre 1930 a 1950 con el cual el filósofo francés logró permear las estructuras fascistas y nazistas lo que condujo a que su teoría personalista encontrara su máximo eco después de acabada la Segunda Guerra Mundial y con su personalismo comunitario le diera a la Europa de la posguerra bases para proponer en sus constituciones un Estado social de derecho, pues su influencia fue notable en la declaración de la ONU sobre los derechos humanos. Además, no se puede olvidar que para difundir su pensamiento creó la revista Esprit (Espíritu) en 1932, la cual tenía como propósito reflexionar sobre la necesidad de romper las formas estáticas en las que se materializaban la cultura y la sociedad burguesa de la época.

Es innegable que el pensamiento personalista de Mounier influyó en las constituciones políticas de Occidente que comenzaron a proclamar un Estado social de derecho en la segunda mitad del siglo XX. De ahí que sea concebible reflexionar que el preámbulo y el artículo primero de la Constitución colombiana de 1991, no solo sean el faro ético de la Carta Magna, sino que reflejen la antropología filosófica de la misma, y en ellos hay argumentos que pueden relacionarse perfectamente con el filósofo francés.

territoriales, democrática, participativa y pluralista, fundada en el respeto de la dignidad humana, en el trabajo y la solidaridad de las personas que la integran y en la prevalencia del interés general. 
Para Mounier el personalismo no era un sistema filosófico ni mucho menos una corriente política, sino una forma de observar los problemas humanos. Esta postura se hace patente en el preámbulo de la Constitución de 1991 que señala las siguientes preocupaciones:

El pueblo de Colombia, en ejercicio de su poder soberano [...] y con el fin de fortalecer la unidad de la Nación y asegurar a sus integrantes la vida, la convivencia, el trabajo, la justicia, la igualdad, el conocimiento, la igualdad y la paz, [...] que garantice un orden político, económico y social justo, y comprometido a impulsar la integración de la comunidad latinoamericana [...].

Es decir, un pueblo que pide las condiciones mínimas de existencia para vivir en sociedad, y a ello se puede agregar lo que expresa el artículo primero de la Constitución: "Colombia es un Estado social de derecho, [...] fundado en el respeto de la dignidad humana, en el trabajo y la solidaridad de las personas que la integran y en la prevalencia del interés general". Ante la crisis de humanismo presente en la época de Mounier, solo era posible para él pensar en un Estado en el que la persona fuera el centro de reflexión filosófica, política, económica y social.

La metodología del presente trabajo consistió en un análisis histórico del contexto vivido por Mounier y el contexto que originó la Constitución de 1991 en Colombia, además de la lectura de textos del autor francés y de doctrinantes del derecho constitucional y la filosofía del derecho, principalmente colombianos. En consonancia con lo anterior, el objetivo fue determinar la incidencia del pensamiento del autor francés en la Constitución Polí tica de Colombia mediante el análisis del concepto de Estado social de derecho en el artículo primero de esta Constitución, para establecer la herencia del personalismo en la filosofía de la Carta.

Se trabajarán, entonces, tres temas que harán referencia a lo siguiente: primero, analizar el contexto del personalismo de Emmanuel Mounier en relación con el de la Constitución Política de Colombia de 1991; segundo, analizar la tesis del personalismo de Emmanuel Mounier concordante con el preámbulo y el artículo primero de la Constitución colombiana, $y$, tercero, analizar el concepto del respeto a la dignidad humana como un instrumento filosófico de la Constitución colombiana de 1991.

\section{CONTEXTO DE LA TEORÍA PERSONALISTA DE EMMANUEL MOUNIER Y DE LA CONSTITUCIÓN POLIITICA DE COLOMBIA DE 1991}

Emmanuel Mounier fue un filósofo francés que nació el 1 de abril de 1905 en Grenoble y murió el 22 de marzo de 1950 en Chätenay-Malabry. Fue un pensador cristiano que se preocupó por la proble mática social y política de la época. Luego de terminar su bachillerato comenzó a estudiar Medicina, profesión que abandonó para terminar sus estudios de Filosofía los cuales adelantó desde 1924 hasta 1927. Valga anotar que el profesor que orientó 
su vocación filosófica fue Jacques Chevalier (1882-1962)².

En la sociedad en la que le correspondió vivir se dieron las dos guerras mundiales: la primera desde el 28 de julio de 1914 hasta el 11 de noviembre de 1918, y la segunda desde el 1 de septiembre de 1939 hasta el 7 de mayo de 1945, fecha en la cual se rindieron los alemanes; luego, el 2 de septiembre del mismo año se rindieron los japoneses; además, se presentó el auge del marxismo-leninismo, la hegemonía del liberalismo capitalista y un predominio de distintas formas de exclusión social.

Lo anterior provocó su activismo filosófico que empezó a ejercer con la creación de la revista Esprit en 1932. La publicación tenía como propósito reflexionar filosóficamente acerca de la problemática de la época desde el punto de vista político y social. Sus ataques más frontales los dirigió al capitalismo, al marxismo, al nazismo y al fascismo con la idea de crear una sociedad más humana donde la persona fuera valorada desde su dignidad y libertad.

La finalidad de su publicación y su protesta antropológica y filosófica, en su momento, se pueden sintetizar con la siguiente expresión de Blázquez:

Redimir al hombre - escribió- hacerle salir de una miseria física y moral, a fin que pueda acercarse,

Fue un filósofo francés que estudió en la Universidad de Oxford y era especialista en la filosofía platónica. con un mínimo de disponibilidad, a los valores del espíritu, denunciar en todo momento el fariseísmo abierto, latente de una sociedad que se llama cristiana y que, sin embargo, oprime al hombre con sus estructuras alienantes (1972, p.13)

Entre 1932 y 1939, se publicaron 82 números de la revista Esprit, siendo el año menos productivo 1932 con solo 3 publicaciones y los más productivos 1937 y 1938 con 12 publicaciones en cada año3.

Así, entonces, su corriente filosófica personalista surge en la década de 1930 con la creación de la revista Esprit cuando Europa vivía momentos de crisis económica, política y social, pues, después del término de la Primera Guerra Mundial, además de la inestabilidad política causada por las democracias parlamentarias, Europa se confundió entre el liberalismo capitalista que sufrió la más devastadora caída de valores en la bolsa de los Estados Unidos lo que generó la gran depresión mundial de todos los tiempos con el crack de 1929 en Wall Street; la ideología marxista en la unión Soviética con Lenin (1870-1924) y el fascismo guiado por Benito Mussolini (1883-1945) que era una tercera vía junto con el nacionalsocialismo (nazismo) alemán orientado por Adolf Hitler (18891945).

El régimen fascista gobernó a Italia desde 1922 hasta 1945 de la mano del Duce

\footnotetext{
Véase Biblioteca Nacional de Francia (1932). Números disponibles de la revista Esprit de Emmanuel Mounier. Fecha de consulta: 14 de noviembre de 2016. Disponible en http://gallica.bnf.fr/ark:/12148/ cb34357004j/date
} 
(General) y el régimen nazista lideró a Alemania desde 1933 hasta 1945 a las órdenes del Führer (Líder). Según Burgos:

\begin{abstract}
El fascismo y el nazismo reaccionaban contra la falta de valores del individualismo, contra un parlamentarismo débil que parecía incapaz de gobernar la sociedad y se hacían adalides de la lucha contra un comunismo que se mostraba dispuesto a anegar Europa con su revolución (2012, p. 24-25).
\end{abstract}

Esa fue la lucha dura de Mounier: hacer eco en una Europa dividida y amenazada por el comunismo, el fascismo y el nazismo, "ismos" que desconocían por su propia naturaleza y finalidad el respeto a la dignidad humana. Por lo tanto, en ese sentido, se fortalece más el pensamiento del autor francés cuando, a partir de 1945, después de terminar la Segunda Guerra Mundial, la pregunta filosófica fundamental en el continente europeo hacía relación, justamente, al sentido de la existencia humana y al valor de la dignidad de la persona humana. La respuesta a la misma quedó consignada no solamente en declaraciones de derechos humanos, sino en las constituciones de varios países occidentales, como el nuestro, que querían rescatar el valor de la persona humana en la convivencia social.

La situación descrita muestra un cuerpo de acontecimientos suficientes y necesarios para preocupar a cualquier filósofo de la época. Mounier, por ello, busca por medio de sus publicaciones comprender la necesidad de responderle a Europa sobre la crisis existencial que se vivía desde el punto de vista social, moral e intelectual. Para el filósofo francés, una filosofía que no se comprometiera con lo cotidiano y concreto de la existencia humana no servía: por ello, en la edición de noviembre de 1934 de la revista Esprit, Mounier afirmó:
El hombre no es ni ángel ni bes- tia. Ni espiritual ni carnal. Es, a la vez, lo uno y lo otro. El hombre es una planta enraizada en la tierra, de la que extrae su sus- tancia, mantenido por el ritmo de su destino, pero un destino superior atraviesa su vida como una corriente de savia que, sin arrancarle de su suelo, le llama cada vez más arriba.

Varios autores de esa época se pronunciaron sobre la realidad que se vivía; al respecto, Stefan Zweig ${ }^{4}$ describía el contexto de Europa en la Segunda Guerra Mundial de la siguiente forma:

$$
\begin{aligned}
& \text { Por mi vida han galopado todos } \\
& \text { los corceles amarillentos del } \\
& \text { apocalipsis, la revolución y el } \\
& \text { hambre, la inflación y el terror, } \\
& \text { las epidemias y la emigración; } \\
& \text { he visto nacer y expandirse ante } \\
& \text { mis propios ojos las grandes } \\
& \text { ideologías de masas: el fascismo } \\
& \text { en Italia, el nacionalsocialismo } \\
& \text { en Alemania, el bolchevismo en } \\
& \text { Rusia y, sobre todo, la peor de } \\
& \text { todas las pestes: el nacionalismo, } \\
& \text { que envenena la flor de nuestra } \\
& \text { cultura europea. Me he visto } \\
& \text { obligado a ser testigo indefenso } \\
& \text { e impotente de la inconcebible } \\
& \text { caída de la humanidad en una }
\end{aligned}
$$

4 Escritor y activista social austríaco (1881-1942). 
barbarie como no se ha visto en tiempos y que esgrimía su dogma deliberado y programático de la antihumanidad (2002, p. 13).

Ante tan real descripción del tiempo en que vivía Mounier, hay que precisar que las propuestas personalistas del filósofo francés fueron analizadas en la posguerra, pues sus ideas iban más allá de lo que vivió él entre 1914 y 1945, época en la cual los hechos demostraron que la persona humana no era valorada como centro de ninguna corriente política; más bien era una condición masacrada por las ideologías y los egocentrismos estatales y políticos que dieron origen a las dos guerras mundiales en la primera mitad del siglo XX.

Mounier se definía de la siguiente forma: "soy un montañés, temperamentalmente ingenuo y rústico en mis aficiones, espontáneo; estoy hecho más para la contemplación soñadora del cielo y de la tierra, que para las decisiones y los dogmatismos" (1956, p. 20).

Valga anotar que el afán de Mounier con la revista Esprit era que su pensamiento fuera reflexionado como protesta contra los regímenes absolutistas de los que era testigo y que la política europea entendiera que el camino a seguir era darle sentido y valor al ser humano en cuanto a su dignidad y libertad. Sin embargo, en 1993, Paul Ricoeur ${ }^{5}$ escribió un artículo en referencia a los 50 años de creación de la

5 Paul Ricoeur (1913-2005). Filósofo y antropólogo francés. Experto en temas de fenomenología y hermenéutica filosófica. revista Esprit titulado Muere el personalismo, vuelve la persona, en el cual explicaba que la corriente personalista de Mounier no fue lo suficientemente competitiva para enfrentarse al estructuralismo, al marxismo y al existencialismo de la época. Además, la muerte temprana del autor influyó en el olvido de la teoría personalista porque su filosofía aún no se había fortalecido lo suficiente para permear el contexto social y cultural de Europa. Para Ricoeur "el personalismo se encontraba, así, sacudido por la misma acusación de infamia de sus dos hermanos enemigos (existencialismo y marxismo)" (1993, p. 97).

Ricoeur (1993) criticaba el fin de los "ismos" en la filosofía occidental; por ello consideraba que el personalismo no tuvo la fortaleza suficiente de sostenerse social y políticamente en Europa, y por ello, para él, el personalismo había muerto prácticamente con la muerte de su fundador en 1950. Sin embargo, hubo pensadores europeos posteriores a la muerte de Mounier que continuaron con su legado de manera directa o indirecta y que en sus propuestas mostraban interés por el planteamiento filosófico de las teorías del personalismo.

Pero es de anotar que lo que no murió fue la importancia de la dignidad de la persona humana propuesta por Mounier desde que creó la corriente personalista. Al respecto Ricoeur expresaba:

iVuelve la persona! No insisto en la fecundidad política económica y social de la idea de persona. Baste evocar un solo problema: el 
de la defensa de los derechos del hombre, en otros países distintos al nuestro, o el de los derechos de los prisioneros y de los detenidos en nuestro país, o incluso los difíciles casos de conciencia... ¿Cómo se podría argumentar en ninguno de estos casos sin referencia a la persona? Si la persona vuelve es porque ella sigue siendo el mejor candidato para sostener los combates jurídicos, políticos, económicos y sociales evocados (1993, p. 98).

Lo anteriormente expresado permite afirmar que el concepto de persona y el respeto por su dignidad fue la preocupación que los Estados privilegiaron para construir las bases constitucionales de sus sociedades. Pero, además, surgieron varios pensadores, posteriores a la muerte de Mounier, que compartieron su corriente e impactaron en el mundo occidental en la segunda mitad del siglo XX. Al respecto, Burgos hace una relación de autores que fundamentaban algunas de sus tesis en la teoría personalista de Mounier:

Para dibujar un cuadro completo hay que ampliar la corriente francesa con pensadores como Jacques Maritain, Gabriel Marcel y Nédoncelle, el personalista metafísico. Y además y sobre todo hay que extenderlo a otros países y matrices especulativas que vayan más allá del personalismo comunitario. La matriz dialógica aporta pensadores de la talla de Buber, Ebner, Rosenzweig y, más recientemente, Lévinas. En la matriz fenomenológica encontramos, entre otros, a Scheler, Von Hildebrand y Stein. Karol Wojtyla es el principal representante de la numerosa escuela polaca. En Italia, entre otros podemos mencionar a Carlini, Luigi Pareyson y Luigi Stefanini. Ya hemos hablado de Romano Guardini, pero se puede señalar también a Seifert, Crosby y, en España, a Zubiri, López Quintás, Laín Entralgo, Díaz, Manzana, Burgos y, en un sentido que habría que determinar, Julián Marías. Todo esto sin mencionar la vertiente teológica, que existe. Este elenco de figuras refleja, esta vez sí, de modo sustancialmente global, el cuadro de la filosofía personalista (2009, p. 20).

Ahora bien, en relación con el contexto de la votación y construcción de la Constitución Política de 1991, en Colombia se padecía una lucha cruel y violenta en la que el actuar al margen de la ley tanto del narcotráfico como de las guerrillas y de los paramilitares ponía al país permanentemente en Estado de conmoción interior. Esto llevó a que la nación volviera a pensar en la posibilidad de un cambio de la Constitución Política de 1886. Al respecto Bushnell afirma que "el notorio aumento de la violencia política se vio complementado por la violencia resultante de un masivo tráfico de drogas" (2007, p. 353).

Políticamente, desde 1978, se había terminado el pacto conocido como Frente Nacional que consistía en una coalición política y electoral entre los dos partidos más tradicionales de Colombia (Conservador y Liberal) desde 1958 hasta 1974. Cada cuatro años gobernaba un partido diferente, pero administraba con un 50\% de miembros del otro partido. 
El primer momento de cambio político y social que se dio para la propuesta de una nueva Constitución ocurrió con el presidente de la República de Colombia del período de 1982 a 1986, Belisario Antonio Betancur Cuartas, abogado antioqueño y político del Partido Conservador que tenía como lema de su campaña lograr la paz con la guerrilla colombiana, pero le tocó enfrentar una crisis financiera, política y de seguridad frente a grupos al margen de la ley como el narcotráfico (cártel de Medellín y de Cali), la guerrilla (M-19, FARC-EP, ELN, EPL) y los grupos paramilitares (civiles armados contra la guerrilla auspiciados por agentes del Estado) que desestabilizaron política y jurídicamente el país. Fruto de ello, desde 1984 hasta 1990, se presentaron muertes de civiles inocentes y miembros del Estado, no solo militares sino ministros, congresistas, candidatos presidenciales, magistrados de las altas cortes y jefes de órganos de control del Estado -como los procuradores $^{6}$ - dejando un baño injustificado

6 Rodrigo Lara Bonilla (1946-1984) político y abogado, al momento de su muerte era el Ministro de Justicia de la República de Colombia y fue sacrificado por un menor de edad al servicio del cártel de Medellín el 30 de abril de 1984. El 6 de noviembre de 1985 el M-19, auspiciado por el cártel de Medellín, asaltó el Palacio de Justicia donde trabajaba la Corte Suprema de Justicia y fueron sacrificados sin ninguna consideración varios civiles y 11 magistrados. Carlos Mauro Hoyos Jiménez (1939-1988) abogado de la Universidad de Medellín, especialista en Derecho Constitucional, se posesionó como Procurador General de la Nación el 17 de septiembre de 1987 y fue secuestrado y ejecutado por el cártel de Medellín el 25 de enero de 1988. Luis Carlos Galán Sarmiento (1943-1989) abogado, economista, periodista y político colombiano, candidato presidencial para las elecciones de 1982 y 1990, jefe del partido Nuevo Liberalismo y quien expulsó a Pablo Escobar de su partido en 1982 fue de sangre con los miles de víctimas que padecieron el sinsentido de la existencia humana en nuestro territorio. Al respecto, Bushnell afirma que "el tejido social, anotaban algunos, se estaba deshaciendo" (2007, p. 353).

Ante tal panorama tan inhumano, en el que la barbarie prevalecía sobre la civilización, y la indiferencia y la insensibilidad sobre el diálogo racional, la población en Colombia pedía un cambio de Constitución en el que la seguridad ciudadana y el respeto a la dignidad humana prevalecieran y fuera un pacto ciudadano que se respetara política y jurídicamente. Ello dio origen a que en 1989 se comenzara a discutir la posibilidad de un cambio constitucional en Colombia, el cual podía ser posible convocando a una Asamblea Nacional Constituyente en las elecciones más próximas que eran las de marzo de 1990. El hecho se produjo el 11 de marzo de 1990 cuando los ciudadanos votaron por siete elecciones, aunque solo seis se contabilizaron por la Registraduría Nacional del Estado Civil, por considerar la séptima opción como algo inconstitucional.

Fue entonces, en las postrimerías del gobierno del presidente Virgilio Barco Vargas (1921-1997), ingeniero civil y militante

asesinado el 18 de agosto de 1989 por el cártel de Medellín. Luego de la muerte de Luis Carlos Galán, el 27 de noviembre de 1989, el cártel de Medellín puso y activó en pleno trayecto una bomba en el vuelo 023 de la aerolínea Avianca, pretendiendo matar al entonces candidato presidencial César Gaviria Trujillo quien fue el que reemplazó a Galán en la campaña presidencial, objetivo que no logró pues este último fue presidente de Colombia 19901994, pero en dicho acontecimiento murieron todos los ocupantes del avión, 110 personas. 
del Partido Liberal, cuando se expidió el Decreto de Estado de Sitio 927 de mayo de 1990 que ordenaba a la Registraduría Nacional del Estado Civil contar los votos de la séptima papeleta ${ }^{7}$. Dicha potestad se la daba el artículo 121 de la Constitución de 1886 al ejecutivo; al respecto Valderrama afirma que "el Estado estaba en crisis institucional y el pueblo quería colaborar en la superación de esa crisis" (2013, p. 132). Según Cajas, la séptima papeleta señalaba textualmente que "Para fortalecer la democracia participativa, voto por la convocatoria de una Asamblea Constitucional con representación de las fuerzas sociales, políticas y regionales de la nación, integrada democrática y popularmente para reformar la Constitución Política de Colombia" (2008, p. 86).

Esta decisión del Gobierno fue acogida por la Corte Suprema de Justicia (1990), quien expresó al respecto que:

\section{El clamor popular para que ocurra el fortalecimiento institucional es un hecho público y notorio que en derecho no requiere prueba; a favor de él se han manifestado los partidos políticos, los medios de comunicación, los estamen- tos universitarios y el pueblo en general.}

La séptima papeleta fue una propuesta surgida de un movimiento nacional estudiantil a finales de 1989, cuyo propósito era solicitar un séptimo voto para pedir una reforma constitucional mediante la convocatoria a una Asamblea Nacional Constituyente en las jornadas electorales del 11 de marzo de 1990, las cuales estaban previstas para seis elecciones (Senado, Cámara de Representantes, Asambleas Departamentales, Concejo Municipal,

Alcaldías y Juntas Administradoras locales -JAL-).
En ese sentido, el nuevo gobierno del presidente César Gaviria Trujillo (19901994), mediante Decreto Legislativo 1926 de agosto 24 de 1990, dictó medidas tendientes a restablecer el orden público y convocó a una Asamblea Nacional Constituyente que reformara la Constitución Política de 1886, en el marco de un gran debate nacional sobre cambios institucionales.

Sobre la constitucionalidad de dicho Decreto se pronunció la Corte Suprema de Justicia, según Sentencia 138 del 9 de octubre de 1990 en la que, de los 27 magistrados, 12 se pronunciaron mediante salvamento de voto y 15 votaron a favor de la convocatoria a la elección de una Asamblea Nacional Constituyente que reformara la Constitución Política de 1886. Al respecto, Valderrama señala que "en ella volvió a pronunciarse política y jurídicamente sobre la relevancia jerárquica del poder constituyente primario ${ }^{8}$ en el orden jurídico colombiano y por ello decreta su constitucionalidad" (2013, p. 134).

Por consiguiente, se le dio vía libre a la Asamblea Nacional Constituyente para que decidiera la reforma o la sustitución de la Constitución Política de 1886. En relación con ello, Cajas indica que:

La Corte declara la constitucionalidad del decreto, reinterpretando el concepto de nación de la Constitución vigente, enten-

8 "Voluntad originaria, soberana, suprema y directa que tiene un pueblo, para constituir un Estado dándole una personalidad al mismo y darse la organización jurídica y política que más le convenga." Véase Quisbert, 2001, p. 19. 
diendo que la soberanía nacional reside en el pueblo y no sólo en sus órganos representativos. En consecuencia, determina que la convocatoria a una asamblea nacional constituyente es constitucional por ser un mecanismo en donde el pueblo ejercerá su poder constituyente al elegir una asamblea constituyente que reforme la Constitución vigente (2008, p. 91).

Dado que lo que interesa para este texto es la importancia del ser humano desde el punto de vista político y jurídico, cabe anotar que la Corte Suprema de Justicia, en este caso, se alejó del formalismo jurídico propuesto por los constitucionalistas del momento y pensó en la realidad colombiana, la cual estaba cansada de los vejámenes del conflicto interno en el que la dignidad de las personas era superada por el pensamiento maquiavélico "el fin justifica los medios", entendiendo que el fin era el poder a costa de la vulneración de todos los derechos humanos de la población colombiana.

En ese sentido, la Corte Suprema de Justicia colombiana, siendo realista y equitativa, y entendiendo que más allá de un precepto constitucional está la defensa de la dignidad humana, expresó en la Sentencia 138 del 9 de octubre de 1990 que:

Dentro de la tradición política y jurídica de la República que arranca desde los albores de la Independencia, existe un plexo de convicciones y principios que legitiman la validez del sistema democrático y que de seguro obligarán a los ciudadanos a proceder con la más elevada respon- sabilidad, y a la Asamblea Nacional Constitucional a interpretar las necesidades y esperanzas de la Nación que tiene derecho a buscar nuevos caminos que garanticen un mejor proyecto de vida de normal convivencia, paz, libertad y justicia social.

Era indudable que la Corte Suprema de Justicia, como representante del poder judicial en el Estado colombiano, buscaba una decisión humana que respetara la tradición democrática de nuestro país y garantizara mejores derechos a los colombianos. Frente a la barbarie, las mutilaciones, las decapitaciones, los coches bomba, se sublevó el pueblo colombiano que con el arma democrática del voto logró el aval estatal para pensar en una nueva Constitución, la cual, luego de ser promulgada el 4 de julio de 1991, estableció un Estado social de derecho que se fundamentó en el respeto a la dignidad humana, el trabajo, la solidaridad y la prevalencia del interés general, donde el respeto a los derechos humanos y la justicia social son instrumentos necesarios para mantener el modelo de Estado propuesto.

\section{EL PERSONALISMO DE MOUNIER YSU RELACIÓN CON EL CONTEXTO DE LA CONSTITUCIÓN POLIITICA DE COLOMBIA DE 1991}

Un dato biográfico interesante en Mounier es que el pensador nunca se encontró completamente a gusto en las aulas universitarias, ni cuando estudió Medicina ni cuando optó por Filosofía debido, principalmente, a que en la universidad se idealizaba el mundo sin que mediara 
un verdadero compromiso con el resto de los seres humanos. Para Mounier tanto la filosofía como el arte, la religión y la moral, y cualquier otro quehacer humano, debían ser, en primera instancia, para el hombre y la mujer que se dan realmente en la historia y que viven su propia vida, para el ciudadano que muestra su cara de angustia, sufrimiento o alegría, porque "una filosofía que no fuese comprometida, no sirve". En ese sentido, para el autor francés, en la enseñanza universitaria era necesario unir pensamiento y acción para no quedar marginado en este mundo concreto y real (Araya, 1990, p. 136).

La filosofía de Emmanuel Mounier no evadía la realidad que circundaba al ser humano en ese contexto histórico que le tocó vivir. Su pensamiento filosófico siempre fue crítico de las teorías idealistas, especulativas y abstractas plenas; además, escribía en razón a lo real y no a lo artificial, porque la filosofía, según él, debía apuntar a la historia real y concreta del ser humano; de ahí su crítica a la filosofía clásica por idealista, abstracta y desenraizada del existir concreto, la que catalogaba como una teoría filosófica de pensamiento sin acción y, por consiguiente, sin sentido. Su filosofía se ocupa de la persona de carne y hueso, sensible, que llora y ríe. Es decir, una filosofía de compromiso permanente con la vida, pues una de sus principales preocupaciones era el desorden establecido en Europa desde el punto de vista social, económico y político (Araya, 1990, p. 136).

La situación histórica que se vivía en Colombia a finales de la década de 1980 y en el momento de decidir si se derogaba la Constitución de 1886 por otra también era de desesperación existencial como en los tiempos de Mounier. Como lo escribían Palacios y Safford:
En esta ocasión el enemigo era el narcotráfico, que desde 1988 había desatado una fulminante guerra terrorista, sin cuartel y en ascenso. Uno de los episodios más alarmantes de esta campa- ña fue el asesinato del jefe del partido liberal Luis Carlos Galán Sarmiento ${ }^{9}$ quien, como Gaitán ${ }^{10}$, en 1948, iba camino a la presiden- cia (2012, p. 480).

En ese sentido, en los dos momentos históricos que se analizan en este trabajo, la situación era desesperante desde el punto de vista humano, el valor de la persona y su dignificación poco importaban, la guerra, el terror y la violencia eran instrumentos valiosos tanto del Estado como de grupos terroristas al margen de la ley para obtener sus objetivos, pues ellos también eran la representación del capitalismo burgués. Como lo expresaba Mounier:

\section{Lo que era preciso reprochar a la civilización técnica no es el ser inhumana en sí, sino el hecho de}

\footnotetext{
Luis Carlos Galán Sarmiento (1943-1989). Abogado, economista, periodista y político colombiano, asesinado por los sicarios del narcotraficante Pablo Escobar Gaviria cuando era el firme candidato a la presidencia de Colombia en 1990.

10 Jorge Eliécer Gaitán Ayala (1903-1948). Abogado y político colombiano, asesinado el 9 de abril de 1948 siendo candidato a la presidencia. Su asesinato fue lo que dio origen al periodo conocido como el de la violencia en Colombia, el cual ha perdurado hasta nuestros días.
} 
no estar aún humanizada y, de servir a un régimen inhumano..., el capitalismo burgués ahoga paulatina e inhumanamente a la persona haciendo ver como natural la miseria humana (1965, p. 76).

Al respecto, Palacios y Safford (2012) indican que:

\begin{abstract}
A finales de la década de 1980, los valores y prácticas subyacentes de la política informal seguían determinando la vida pública, aparte o contra la normativa, conforme al conocido proverbio político latinoamericano: 'para los enemigos, la ley; para los amigos, el favor'. Por otra parte, se multiplicaron los problemas asociados con el narcotráfico y la guerrilla (p. 479).
\end{abstract}

En las dos épocas, la barbarie, los vejámenes, la falta de solidaridad, la pobreza y la miseria humana eran indiscutibles. Por ello, eran necesarios pensamientos activos y reales, sucesos concretos que desviaran el rumbo de la deshumanización. Un capitalismo burgués que, tanto en la época de Mounier como en la del contexto anterior a la Constitución de 1991 en Colombia, generó un desorden social en el que el egoísmo y el dinero evidenciaron diferencias en las poblaciones, donde reinaba la indiferencia y la falta de solidaridad por el otro, donde lo concreto era la injusticia, la irracionalidad y la crueldad. Para Mounier, la necesidad personal era vital para salir del abismo existencial en que se encontraba el ser humano de su tiempo, pues la persona no está dada para subsistir sino para vivir plenamente.
Al respecto, Mounier expresaba que:

El humanismo burgués está esencialmente basado en el divorcio del espíritu y de la materia, del pensamiento y de la acción. Desde los jóvenes revolucionarios de extrema derecha a los mismos marxistas, defensores y adversarios de lo espiritual, todos se han unido en nuestro tiempo en una crítica unánime, aunque indistintamente fundada, de este idealismo exangüe y ansioso de provecho que se halla en la base de las concepciones burguesas (1965, p. 26-27).

Al igual que en Colombia, como lo afirmaban Palacios y Safford: "en las circunstancias adversas de 1990, miles de colombianos depositaron su confianza en una nueva Constitución y fue visible la participación de grupos de estudiantes universitarios que pedían el cambio constitucional" (2012, p. 481). En esa época se vivía al nivel mundial una ola de transformación política representada en la caída del muro de Berlín ${ }^{11}$, en Alemania y, por consiguiente, el fin del sistema soviético. Se reclamaba por la protección de los derechos humanos y del medio ambiente, por una sociedad civil participativa y por una descentralización política del Estado. Todo ello era lo que precisamente se pedía que quedara en la nueva Constitución de 1991.

"Era un muro de seguridad, que dividió la Alemania oriental comunista de la Alemania occidental capitalista. Tenía una altura de 3.6 metros y un perímetro de 155 kilómetros. Funcionó desde el 13 de agosto de 1961 hasta el 9 de noviembre de 1989. Era el verdadero símbolo de la Guerra Fría entre la Unión Soviética y Occidente. 
Es de advertir que la Constitución Política de Colombia de 1991, desde su preámbulo y el artículo primero, constituyó a la persona y su dignidad como el faro que debía iluminar no solo toda la Constitución sino el orden jurídico colombiano. En el preámbulo se expresa antropológicamente una serie de valores que le dan significado a la existencia humana: "el Pueblo de Colombia [...], con el fin de asegurar a sus integrantes la vida, la convivencia, el trabajo, la justicia, la igualdad, el conocimiento, la libertad y la paz [...]", algo que era predicado filosóficamente por Mounier, no solo en la revista Esprit, sino también en sus textos. Al igual que en el preámbulo se habla "de un marco jurídico, democrático y participativo que garantice un orden político, económico y social justo", en concordancia con el pensador francés que reclamaba democracia, mas no tiranías como la fascista y la nazista, y su finalidad filosófica era rescatar la dignidad de la persona humana para formar una sociedad justa.

El filósofo francés buscaba rescatar esos valores de la persona humana para que tuviera sentido su existencia, por ello Mounier señalaba que:

Una persona es un ser espiritual constituido como tal por una forma de subsistencia mediante su adhesión a una jerarquía de valores libremente adoptados, asimilados y vividos por un compromiso responsable y una constante conversión; de este modo unifica toda su actividad en la libertad, desarrollando, además, a fuerza de actos creadores, lo singular de su vocación (1965, p. 44).
No es casualidad, entonces, que algunas constituciones después de la segunda mitad del siglo XX hayan acogido el pensamiento de Mounier para establecer el Estado social de derecho, que buscó ser contrario a los Estados tiránicos y que tiene como finalidad garantizar las condiciones mínimas para existir dignamente y no para sobrevivir, como expresaba Mounier.

Ante la decepción y desesperación de personas sin sentido existencial, se tenían dos opciones en cada contexto: por un lado, la nihilista cosificadora de la existencia humana y practicada por las tiranías después de la Primera y la Segunda Guerra Mundial o, por otro lado, la opción esperanzadora de construir un tejido social para vivir más dignamente como seres humanos. En ambos contextos se escogió la segunda, pero en el caso colombiano no hubo convicción de verdadero cambio, pues el país quedó fragmentado y, por lo tanto, la sociedad dividida, tal cual lo expresan Palacios y Safford:
Los desarrollos legales de la Constitución quedaron en manos de la clase política preconstitu- yente. El problema de fondo sigue siendo el mismo desde la funda- ción de la República: la distancia entre los sueños del constitucio- nalismo y las prácticas sociales (2012, p. 483).

En consecuencia, si se analizan los valores expresos en el preámbulo de la Constitución Política de Colombia de 1991, como la vida, la convivencia, el trabajo, la justicia, la igualdad, el conocimiento, la libertad y la paz, lo que se buscaba con 
ello era que el Estado garantizara que su pretensión era no cosificar al ser humano, más bien, que se respetara su vida, que se buscara un orden jurídico que permitiera la convivencia, que garantizara igualdad de oportunidades para la población y que se pudiera acceder a un trabajo digno, que la justicia fuera pronta, coherente y efectiva, que se respetara la dignidad humana para asegurar la igualdad entre las personas, que se diera la posibilidad de que la población se educara y obtu viera el conocimiento necesario para ser un ciudadano participativo, que se garantizara la libertad humana en todas su expresiones y que la meta fuera vivir en una sociedad en paz. Tal cual lo expresaba Mounier cuando aseguraba que "la persona humana no es una cosa, ni un objeto y mucho menos, un medio para obtener un fin" (1965, p. 73).

Además, política y socialmente el preámbulo de la Constitución colombiana alude a un marco jurídico, democrático y participativo que garantiza un orden político, económico y social justo. Es decir, un Estado democrático que tiene un ordenamiento jurídico que posibilita la participación del pueblo y reconoce su poder constituyente primario, con el fin de asegurar un orden justo tanto en el nivel político, como en el social y en el económico.

Al respecto Mounier aseguraba "que es fundamental la base de una civilización dedicada a la persona humana" (1965, p. 75). No es difícil, por lo tanto, deducir que el pensamiento de Mounier se encuentra inmerso en las constituciones que pro- clamaron un Estado social de derecho después de la Segunda Guerra Mundial, como la Carta Magna de 1991. Es por ello que no se puede decir que la Constitución de 1991 genera un nuevo derecho, sino que es el resultado histórico de corrientes filosóficas y hermenéuticas en beneficio del derecho y que han servido para que la interpretación y aplicación de la Constitución colombiana de 1991 tenga como fundamento el respeto a la dignidad de la persona humana.

La persona a la cual se refería Mounier era socialmente activa y comprometida con la transformación concreta de la sociedad. El pensamiento del autor francés no se fundamentaba en el idealismo o en el nihilismo; la base de su pensamiento es la existencia concreta de la persona humana, una persona cuyo valor primordial es la libertad tanto para actuar como para elegir. Al respecto Mounier afirma que:
La persona no es objeto de una experiencia espiritual pura, sepa- rada de todo trabajo de la razón y de todo dato sensible. Se re- vela, sin embargo, mediante una experiencia decisiva, propuesta a la libertad de cada uno; no la experiencia inmediata de una sustancia, sino la experiencia progresiva de una vida, la vida personal. Ninguna noción puede sustituirla (1965, p. 44).

Es de anotar que el fundamento de la persona que se discutía en tiempos de la Constitución Política colombiana de 1991 era totalmente realista, acorde con los valores colombianos de orden, convivencia, justicia, libertad y paz y se vivía 
un rechazo a factores reales de poder al margen de la ley como el narcotráfico, las guerrillas y los paramilitares que desde el terrorismo destruían al ser humano sin consideración alguna y un idealismo de las corrientes políticas del momento que buscaban, desde un discurso existencialista, una mejor protección a la persona humana en lo social, lo político, lo económico ofreciendo así un modelo de Estado que garantizara las condiciones mínimas para la existencia digna de la persona.

En consecuencia, el personalismo es una corriente que perduró en la segunda mitad del siglo XX a pesar de la muerte repentina del escritor francés en 1950 a sus 45 años de vida. Personajes históricos como Karol Josef Wojtyla ${ }^{12}$ lograron continuar con el pensamiento de Mounier en las décadas posteriores a su muerte e hicieron de esa teoría una realidad en defensa de la persona humana como sujeto digno de respeto por su libertad, lo cual se vio reflejado en las constituciones europeas y latinoamericanas.

\section{EL CONCEPTO DEL RESPETO A LA DIGNIDAD HUMANA COMO UN INSTRUMENTO FILOSÓFICO DE LA CONSTITUCIÓN COLOMBIANA DE 1991}

Atendiendo al significado del concepto de dignidad humana, se ofrecen, en un

12 Obispo polaco (1920-2005), Sumo Pontífice del catolicismo bajo el nombre de Juan Pablo II. Ejerció su pontificado por 27 años (1978-2005). No solo fue el máximo líder religioso de los católicos, sino que su liderazgo político logró que se acabara la Guerra Fría entre la Unión Soviética y Estados Unidos y fruto de ello fue la caída del muro de Berlín (Alemania). primer momento, algunas definiciones del término para luego entrar a relacionarlo con las constituciones occidentales de la segunda mitad del siglo XX, principalmente la colombiana de 1991. Si se fuese a dar significado al concepto de dignidad humana, se encontrará que en todo caso el inicio y el fin de ella misma es la persona.

Hoyos afirma que "la dignidad de la persona y su expresión jurídica, es decir, los derechos que se derivan de ella, son algunos de esos principios que se constituyen en el supuesto de toda Constitución y de toda regulación sobre los derechos humanos" (1996, p.103). El mismo autor señala también que "la dignidad significa excelencia, eminencia, grandeza y superioridad. Todo hombre tiene, en tanto ser creado, excelencia, eminencia y superioridad en el ser. Los derechos naturales -hoy llamados derechos humanos- son la expresión jurídica de la dignidad de la persona humana" (2000, p. 78).

Por su parte, Villán (2002) afirma que "la dignidad humana es la única idea-fuerza que aglutina las diversas concepciones culturales, filosóficas, políticas religiosas, morales y sociales presentes en el mundo contemporáneo" (2002, p.34). A su vez, Valderrama indica que:

La dignidad humana es un elemento antropológico anterior al concepto de Estado y surgido en el mismo origen del ser humano, la dignidad humana, es una condición inherente al ser humano y que solo se entiende desde lo humano y para lo humano, en el ámbito de la interpretación jurídica, la dignidad humana es 
un concepto antropológico con sentido axiológico y no patrimonial (2013, pp. 152-153).

Finalmente, en la Sentencia T 411 de 1992, la Corte Constitucional dice que:

La persona a la que se refiere la Constitución, no es el individuo en abstracto, aisladamente considerado, sino precisamente el ser humano en su dimensión social, visto en la tensión individuocomunidad; surge entonces un personalismo social, en el que el valor supremo que representa la persona humana aparece inserto en la comunidad o sociedad organizada. De la dignidad de la persona humana surge la identidad entre las desigualdades. Se supera así el concepto de la igualdad de la ley a partir de la generalidad concreta, que concluye con el principio conforme al cual las situaciones comparables se traten en forma análoga y las situaciones diferentes se traten en forma desigual. Con este concepto se establece la paridad de la dignidad social que solo permite un trato diferente si está razonablemente justificado.

Teniendo en cuenta lo anterior, el texto de Mounier El manifiesto al servicio del personalismo enunciaba, ya desde el título mismo, la primacía de lo irracional y de la fuerza haciendo referencia a una de las finalidades del fascismo y del nazismo. Ese hecho narra por sí solo el poco valor que en ese momento veía el filósofo francés que se le daba a la persona humana; su análisis lo empieza precisamente por el desconocimiento total del respeto por la dignidad humana.
Uno de los autores que más influyó en este tema en Mounier fue el filósofo alemán Immanuel Kant ${ }^{13}$ a través de la formulación filosófica de la dignidad de la persona en razón a la diferencia entre cosa y persona. Al respecto Kant, en un texto por demás clásico, decía que:

\begin{abstract}
Los seres cuya existencia no descansa en nuestra voluntad, sino en la naturaleza, tienen, empero, si son seres irracionales, un valor meramente relativo, como medios, por eso se llaman cosas; en cambio los seres racionales, llámense personas porque su naturaleza los distingue ya como fines en sí mismos, esto es, como algo que no puede ser usado meramente como medio, $\mathrm{y}$, por tanto, limita en todo sentido todo capricho (y es un objeto del respeto) (2003, p. 66).
\end{abstract}

Frente a los peligros existenciales que se vivían en el mundo de ese entonces, donde el nazismo y el fascismo eran verdaderas monarquías tiránicas vulneradoras de los valores humanos y cosificadoras de los seres humanos, el pensamiento de Mounier era una concepción coherente, moderada, y equilibrada de ideas que, frente a los conflictos bélicos de orden mundial, buscaba solucionar problemas individuales y colectivos desde el respeto a la dignidad de la persona y del bien común.

13 Inmanuel Kant (1724-1804). Con él se cierra filosóficamente la edad moderna y comienza la edad contemporánea. Su método filosófico es la crítica, lo cual se evidencia en sus textos Crítica de la razón pura, Crítica del juicio y Crítica de la razón práctica. 
En toda la década de 1980 a 1990, Karol Wojtyla, actuando como Juan Pablo II en su pontificado, logró que la corriente personalista de Mounier resurgiera y se centró en los postulados del respeto a la dignidad humana de la persona, coincidiendo en ese momento con las primeras reflexiones de tinte humanista de la Constitución europea. Ya desde 1964, ejerciendo como arzobispo de Polonia, había expresado que "el Concilio y la Iglesia consideran la llamada acerca de la dignidad de la persona humana como la voz más importante de nuestra era" (Concilio Vaticano II, 1964).

Durante su pontificado sostuvo que el documento Gaudium et Spes era el texto del personalismo cristiano y "la carta magna de la dignidad humana" (Fernández, 2006). En ese sentido, el mundo desde 1945 vivió un cambio político, el cual buscaba obtener mecanismos jurídicos que protegieran y no dejaran vulnerar los derechos humanos para una mejor convivencia universal, y una de las mejores teorías para ese cambio fue el personalismo del filósofo francés que sobre la base de la persona y la acción social se fueron convirtiendo en contenidos básicos de la cultura europea y su proceso de constitucionalización. Sin lugar a dudas, fue el Papa Juan Pablo II quien más hizo resurgir el planteamiento de Mounier a finales del siglo XX.

Para Mounier "la libertad de la persona es la libertad del descubrir por sí misma su vocación y de adoptar libremente los medios de realizarla" (1965, p. 53). Con ello lo que el personalismo buscaba en Europa era enseñar que no puede existir sociedad digna sin respeto a los valores trascendentales y permanentes; de lo contrario, las personas serían esclavizadas por el sistema político y económico. Para el personalismo, ser libre no solo es un derecho, sino que ayuda a la realización existencial.

Colombia no fue ajena al personalismo de Mounier, y la Constitución de Colombia de 1991 tiene como referente filosófico de todo su contenido el artículo primero el cual manifiesta que Colombia es un Estado social de derecho fundamentado en el respeto de la dignidad humana, en el trabajo y la solidaridad de las personas que la integran y en la prevalencia del interés general. Es decir, el Estado social de derecho en Colombia se sostiene en cuatro pilares: el respeto a la dignidad humana, el trabajo, la solidaridad y la prevalencia del interés general. Por lo tanto, nuestro país acogió un elemento central en el constitucionalismo posterior a la Segunda Guerra Mundial que era, además, uno de los pilares del personalismo de Mounier como lo es el respeto a la dignidad humana.

El título I de la Constitución colombiana trata de los principios fundamentales. Al respecto Monroy Cabra señala que entre esos principios "figuran la dignidad humana y la primacía de los derechos inalienables de la persona" (2012, p.139). El título II se denomina De los derechos, las garantías y los deberes, el cual está dividido en cinco capítulos que tratan de los derechos fundamentales; los derechos sociales, económicos y culturales; los derechos colectivos y del ambiente; la protección y 
aplicación de los derechos; y los deberes y obligaciones. Como se puede deducir, la de 1991 es una Constitución garantista de los derechos, y su centro de reflexión es la persona humana.

Por consiguiente, igual que Mounier en su época, la Constitución colombiana vigente introdujo todos los derechos que después de 1945 se habían empezado a establecer en las constituciones europeas, fruto de pensamientos filosóficos de corte humanista como el de Emmanuel Mounier. Al respecto Monroy Cabra expresó que "el fundamento de los derechos humanos se encuentra en el reconocimiento de la dignidad humana, que es un principio, un valor y un derecho fundamental" (2012, p. 133).

El artículo $241^{14}$ de la Constitución colombiana de 1991 le confía la guarda de la integridad y supremacía de la Constitución a la Corte Constitucional colombiana; a su vez, este organismo colegiado ha expresado que la dignidad humana es el fundamento del orden jurídico en Colombia:

La consideración de la persona humana y de su dignidad es el presupuesto y el elemento esencial del nuevo "Estado social de derecho", razón por la cual el sistema constitucional de derechos y garantías - máxima expresión jurídica de la dignidad de la persona humana- contribuye a darle sentido, contenido y fin a

14 Artículo 241. A la Corte Constitucional se le confía la guarda de la integridad y supremacía de la Constitución, en los estrictos y precisos términos de este artículo. esta modalidad de Estado (Corte Constitucional, 1992).

Ahora bien, atendiendo a la evolución de la aplicación jurídica del concepto de la dignidad humana, la Corte Constitucional colombiana le ha dado una interpretación jurídica teniendo en cuenta tres presupuestos existenciales de cada persona: el querer ser, el vivir bien, y el no ser deshonrado. Se presentan, ahora, sentencias de la Corte Constitucional donde se desarrolla cada uno de estos presupuestos.

\section{- Con respecto a la dignidad huma- na y el querer ser persona, la Corte Constitucional señala que:}

La dignidad humana requiere que el hombre actúe según su recta razón y libre elección, movido por la convicción interna personal y no bajo la presión que otros hagan sobre su libertad, porque entonces el acto no sería libre, y al no serlo no puede estar amparado por la legitimidad. El hombre, pues, logra la dignidad cuando se libera totalmente de toda cautividad y cuando pone los medios para que sus semejantes no caigan en dicho estado indigno (Corte Constitucional, 2002).

\section{- En cuanto a la dignidad humana y el vivir bien como persona:}

La dignidad humana descarta toda actitud despectiva frente a las necesidades corporales y espirituales del hombre, todas las cuales merecen atención en el Estado Social de Derecho, que reconoce en el ser humano 
la razón de su existencia y la base y justificación del sistema jurídico. No se garantiza bien, ningún derecho de los que la Constitución califica fundamentales intrínsecos a la persona si a un individuo de la especie humana se le condena a sobrevivir en condiciones inferiores a las que la naturaleza le señale en cuanto a ser humano (Corte Constitucional, 1998).

\section{- La dignidad humana y el no ser deshonrado como persona:}

La dignidad humana exige pues que, al hombre, en el proceso vital, se le respeten también su salud y su integridad física y moral, como bienes necesarios para que el acto de vivir sea digno. De ahí que el derecho a la integridad física y moral consistente en el reconocimiento, respeto y promoción que se le debe a todo individuo de la especie humana, es que su existencia sea conforme a la dignidad personal (Corte Constitucional, 1994).

No hay duda de que la Constitución y la Corte Constitucional colombiana promovieron la reflexión filosófica sobre la importancia de la persona humana como el centro de los postulados jurídicos, políticos y económicos en una sociedad. Esa reflexión no es nueva, es adquirida de pensadores humanistas del siglo XX que sufrieron los vejámenes de las guerras y que esos acontecimientos hicieron que sus ideas se convirtieran en los pilares fundamentales de las constituciones occidentales a partir del 10 de diciembre de 1948 con la Declaración Universal de los
Derechos Humanos, los cuales iban impregnados con teorías humanistas como la personalista de Emmanuel Mounier.

Todo lo anterior, se puede sintetizar con la siguiente argumentación que expresó la Corte Constitucional de Colombia:

\begin{abstract}
El principio de dignidad humana no sería comprensible si el necesario proceso de socialización del individuo se entendiera como una forma de masificación y homogenización integral de su conducta, reductora de toda traza de originalidad y peculiaridad. Si la persona es en sí misma un fin, la búsqueda y el logro incesantes de su destino conforman su razón de ser y a ellas por fuerza acompaña, en cada instante, una inextirpable singularidad de la que se nutre el yo social, la cual expresa un interés y una necesidad radicales del sujeto que no pueden quedar desprotegidas por el derecho a riesgo de convertirlo en cosa (Corte Constitucional, 2013).
\end{abstract}

\section{CONCLUSIONES}

Es indudable que la visión antropológica de la Constitución colombiana de 1991 ha sido el fruto de una evolución filosófica de los pensadores humanistas del siglo XX. Uno de ellos, sin lugar a dudas, es Emmanuel Mounier, quien puso como centro de reflexión de cualquier sistema político a la persona humana y quien, además, buscaba con su corriente personalista ver en la práctica un sistema real y garantista que respaldara jurídica y políticamente el respeto a la dignidad humana de la persona ante el poder del 
Estado. Los cambios jurídicos que se dieron con la Constitución de Colombia en 1991, apuntaron, entre otras cosas, a buscar la aplicación de un derecho más real y menos formal en favor de la persona humana, presupuestos de la corriente de Mounier que filosofaba desde la acción y el compromiso y no desde las meras ideas; por ello buscaba un respeto real por la dignidad humana. La forma de interpretar y aplicar el derecho fue cambiando, entendiendo que primero el respeto era del ciudadano al Estado y hoy es del Estado hacia el ciudadano; de ahí los mecanismos de participación ciudadana para intervenir en la estructura y decisiones del Estado buscando con ello respetar la dignidad de las personas. Nuevas formas de interpretarlo, pues las conductas presentadas en los conglomerados sociales permiten deducir que el derecho siempre mantendrá sus principios y sus fines, pero la aplicación deberá tener en cuenta las innovaciones de comportamiento social del ser humano porque es uno de los fines del derecho.

El personalismo influyó en Occidente en tanto coadyuvó a la madurez democrática de las fuerzas políticas y sociales que han luchado con disposición por los derechos de los ciudadanos y han generado instrumentos eficaces por parte del Estado para una auténtica participación ciudadana. Sin duda alguna, las constituciones de Occidente, después de la Segunda Guerra Mundial comenzaron a centrar su discusión en la persona humana.

Siguiendo el pensamiento de Mounier, la aplicación coherente de ese preámbulo y del artículo primero de la Constitución garantizaría las condiciones mínimas de existencia en un Estado, cualquiera sea su denominación, pues son las herramientas jurídico-políticas que deben utilizar los poderes del Estado y los mismos ciudadanos para solucionar sus conflictos, pero discutiendo siempre sus derechos y obligaciones desde la razonabilidad, la proporcionalidad, el consenso y el respeto por el otro.

En el año de 1991 se consagraron en la Constitución unos valores, principios y derechos que irradiaban al resto del ordenamiento jurídico. Allí se destacaba la dignidad humana como fin último del poder y de la sociedad civil, y se predicaba en todos los contextos sociales y políticos que era una auténtica Constitución humanista. Pero nunca se expresó que la Carta Magna era el resultado histórico de las escuelas hermenéuticas del derecho y de las corrientes filosóficas humanistas del siglo XX entre las que el personalismo de Mounier estuvo presente.

La Constitución colombiana desarrolló los valores que sustentan el humanismo y que son patrimonio de nuestra nación, y desde el respeto a la dignidad humana, la persona es el centro y el punto de referencia de nuestro Estado social de derecho. No hay un término de mayor importancia para el futuro cultural y moral de Latinoamérica, y en especial de Colombia, que el concepto de la dignidad de la persona humana.

Es por ello que el personalismo de Mounier se levantó contra toda imposición 
que atentara contra la dignidad de la persona. El fundamento esencial del personalismo se logra solo desde el reconocimiento de la libertad, la igualdad y la dignidad esencial de las personas. Solo desde ese fundamento se podrán regular los derechos constitucionales, porque los sistemas democráticos se deben instaurar sobre la base del respeto a la dignidad humana de todas las personas.

\section{REFERENCIAS}

Araya, E. (1990). El personalismo cristiano de Emmanuel Mounier: un capítulo de filosofía contemporánea. Revista de Filosofía de la Universidad de Costa Rica, XXVIII (67-68), 135140.

Biblioteca Nacional de Francia (1932). Números disponibles de la Revista Esprit de Emmanuel Mounier. Recuperado de: http://gallica.bnf.fr/ ark:/12148/cb34357004j/date

Blázquez, F. (1972). Emmanuel Mounier. Madrid: Ediciones y publicaciones españolas.

Constitución Política de Colombia de 1991.

Burgos, J. (2012). Introducción al personalismo. Madrid: Ediciones Palabra.

Bushnell, D. (2007). Una nación a pesar de sí misma. Bogotá: Planeta.

Cajas, M. (2008). El control judicial de la reforma constitucional. Colombia 1910-2007. Cali: Universidad Icesi.

Concilio Vaticano II. (1964). Constitución Gaudium et Spes. Barcelona: BAC.

Corte Constitucional. (1992). Sentencia T 571 de octubre 26. M. P. Sanín, J.

Corte Constitucional. (1992). Sentencia T 411 de junio 17. M. P.Martínez, A.
Corte Constitucional. (1994). Sentencia T 123 de marzo 14. M. P. Naranjo Mesa, V.

Corte Constitucional. (1997). Sentencia C 239 de mayo 20. M. P. Gaviria Díaz, C.

Corte Constitucional. (1998). Sentencia T 556 de octubre 6. M. P. Hernández Galindo, J.

Corte Constitucional. (2002). Sentencia T 881 de octubre 17. M. P. Montealegre Lynett, E.

Corte Suprema de Justicia. Sala Plena. (1990). Sentencia 59. Expediente N. ${ }^{\circ} 2149$.

Corte Suprema de Justicia. Sala Plena. (1990). Sentencia 138. Expediente N. ${ }^{\circ} 2214$.

Fernández, J. (2006). El personalismo de Juan Pablo II $y$ el derecho constitucional europeo. Madrid: Conferencia Universidad Complutense de Madrid.

Hoyos, I. (1996). Los derechos humanos: expresión de la recuperación de la dignidad de la persona humana en una época de crisis. Dikaion, (5), 94-128.

Hoyos, I. (2000). La persona y sus derechos. Bogotá: Temis.

Kant, I. (2003). Fundamentación de la metafísica de las costumbres. Madrid: Encuentro.

Monroy, M. (2012). Los derechos humanos en la Constitución de 1991. En J. Vidal y M. Trujillo (eds.). Historia constitucional de Colombia. Tomo III (127-156). Bogotá: Academia Colombiana de Jurisprudencia.

Pouilliart, R. (1958). Mouniere et sa génération. Paris: Seuil.

Mounier, E. (1965). Manifiesto al servicio del personalismo. Madrid: Taurus.

Mounier, E. (1984). El Personalismo. Bogotá: El Búho. 
Palacios, M. y Safford, F. (2012). Historia de Colombia: país fragmentado, sociedad dividida. Bogotá: Universidad de los Andes.

Presidencia de la República. (1990). Decreto Legislativo 1926 del 24 de agosto por el cual se dictan medidas tendientes al restablecimiento del orden público. Diario Oficial 39512 de agosto 24 de 1990.

Quisbert, E. (2001). Poder y asamblea constituyente. Recuperado de: http://web. archive.org/web/20070302172901/www. geocities.com/derechoconstitucional2001/ poderconstituyente archivos/06.pdf

Ricoeur, P. (1993). Amor y justicia. Madrid: Caparrós.

Valderrama, F. (2013). Fundamentos hermenéuticos del Estado social de derecho en Colombia. Medellín: Sello Editorial Universidad de Medellín.

Villán, C. (2002). Curso de derecho internacional de los derechos humanos. Madrid: Trota.

Zweig, S. (2002). El mundo de ayer: memorias de un europeo. Barcelona: Acantilado. 
